\title{
Mild Acid Ultrasonic Assisted Extraction of Arsenic Residues in Different Parts of Hot Chilli Prior to Ultra-Trace Determination by Flow Injection-Hydride Generation Atomic Absorption Spectrometry
}

\author{
SUGUNYA PHONGSIRIRUX, PHITCHAN SRICHAROEN, \\ NUNTICHA LIMCHOOWONG and SAKSIT CHANTHAI*
}

\begin{abstract}
Materials Chemistry Research Center, Department of Chemistry and Center of Excellence for Innovation in Chemistry, Faculty of Science, Khon Kaen University, Khon Kaen 40002, Thailand. "Corresponding author E-mail : sakcha2@kku.ac.th
\end{abstract}

http://dx.doi.org/10.13005/ojc/330526

(Received: July 15, 2017; Accepted: August 08, 2017)

\begin{abstract}
Mild acid ultrasonic assisted extraction (UAE) of arsenic residues in chilli was introduced a sa green approach due to simple, efficient and rapid method in association with flow injectionhydride generation atomic absorption spectrometry (FI-HGAAS). Arsenic species, As'"I and As ${ }^{v}$, were determined in different parts of chilli fruits including seed, pericarb and placenta. This procedure leads to improve mild the extraction conditions using $0.1 \mathrm{~g}$ of ground sample in $10 \mathrm{~mL}$ of $1 \mathrm{M}$ acid mixture of $\mathrm{HCl}: \mathrm{HNO}_{3}(3: 1, \mathrm{v} / \mathrm{v})$ and $1.5 \mathrm{~mL} \mathrm{H}_{2} \mathrm{O}_{2}$ for 15 min sonication. Analytical features of merit for both FI-HGAAS and flame atomic absorption spectrometry (FAAS) measurements were obtained and compared. Actually, trace amounts of total As in these samples were found very lower than limit of quantitation of FAAS. Therefore, the ultra-trace amounts of $\mathrm{As}^{\prime \prime \prime}, \mathrm{As}^{\mathrm{v}}$ and total As in the chilli samples determined by FI-HGAAS were found in the ranges of 1.9-10.2 $\mathrm{ng} \mathrm{g}^{-1}, 1.2-19.1 \mathrm{ng} \mathrm{g}^{-1}, 3.3-$ $22.4 \mathrm{ng} \mathrm{g}^{-1}$, respectively. Among three varieties of these chilli samples, higher contents of As were mostly found in seed of the fruits. The proposed method is, therefore, a novel one and can be implied for a routine work for arsenic in fruits and vegetables with its emerging applications.
\end{abstract}

Keywords: ultrasonic assisted extraction, hydride generation atomic absorption spectrometry, chilli, arsenic.

\section{INTRODUCTION}

Chilli (Capsicum annuum L.) is an important industrial crop of Thailand's economy because of the combination of color, flavor, taste and nutritional value ${ }^{1}$. A large number of biological properties and potential fitness benefits of consuming chilli have been examined such as free radical scavengers, anti-inflammatory, antineoplastic, anti-arthritic, anticancer and antifungal properties $^{2}$. At a global level, environmental pollution due to heavy metals has become a major concern. Arsenic (As) is natural occurring chemical compound. It is also a poisonous metal that can be 
present as inorganic and organic forms at various levels in water, soil, dust, wood, plant and other material. Exposure to As is associated with skin lesions and increased risk of developing cancer of the skin, lungs, liver, kidney and bladder ${ }^{3}$. Arsenic can also occur as residue in chilli due to it can be grown in any variety of soils and people can be exposed to this metal from ingesting contaminated food or water. Its accumulation in the body can lead to harmful effects over time, depending on the dose and toxicity ${ }^{4,5}$. Thus, it is important to determine the species of arsenic in food because of their high toxicity. Various instrumental techniques, such as flame atomic absorption spectrometry (FAAS) ${ }^{6}$, inductively coupled plasma-optical emission spectrometry (ICP-OES) $)^{7,8}$, inductively coupled plasma-mass spectrometry (ICP-MS) ${ }^{9}$, flow injectionhydride generation atomic absorption spectrometric $(\text { FI-HGAAS })^{10}$, UV-Vis spectrop-hotometry ${ }^{11}$, voltammetric method $^{12}$ and colorimetry incorporated with image processing ${ }^{13}$ have been used to accurately and precisely determine As at trace levels in various samples.

Ultrasound-assisted extraction (UAE) is widely used in analytical chemistry to facilitate various steps of some analytical process, particularly sample preparation. They are expeditious, low-cost, and efficient alternatives to old-fashioned extraction techniques ${ }^{14}$. UAE may improve extraction efficiency through disruption of cell walls, particle-size reduction, and improve mass transfer of the cell contents as a result of cavitation. $\mathrm{UAE}$ is an easy, convenient, and rapid way of desorbing inorganic and organic contaminants from sediments, soils and natural samples ${ }^{15,16}$.

This study was aimed to investigate the optimum conditions of UAE under mild acid solution from three varieties of hot chilli as a whole with respect to their seed, pericarb and placenta for the determination of arsenic(III) and arsenic(V) by FIHGAAS and total arsenic by FAAS.

\section{MATERIALS AND METHODS}

\section{Chemicals and reagents}

As'll stock solution (1000 $\left.\mathrm{mg} \mathrm{L}^{-1}\right), \mathrm{As}^{\vee}$ stock solution (1000 $\mathrm{mg} \mathrm{L}^{-1}$ ), and hydrogen peroxide $(30 \%, w / w)$ were obtained from Ajax fine chem
(Australia). Hydrochloric acid (37\%, w/v) and sodium hydroxide were from Carlo Erba (France). Sodium borohydride was from Lab Chem (France). Nitric acid $(65 \%$, w/v) was from Lab Scan Asia (Thailand). Thiourea was from BDH laboratory supplies (England). A Millipore water purification system (Molsheim, France) was used to obtain deionized water with a resistivity of $18.2 \mathrm{M} \Omega \mathrm{cm}$.

All glassware was cleaned by soaking in dilute $1 \%(\mathrm{v} / \mathrm{v}) \mathrm{HNO}_{3}$ overnight and rinsed two times with deionized water prior to use.

\section{Instruments}

Arsenic measurements were made using an atomic absorption spectrometer of the PerkinElmer Instrument AAnalyst 100 (Connecticut, USA) equipped with a flow injection analysis system Model FIAS-100 (Perkin Elmer Instruments, USA), used for continuous flow hydride generation. The FIAS-100 flow injection system consists of one peristaltic pump, five-port valve and a regulated gas control. Argon gas was used as carrier gas for the transposition of arsine $\left(\mathrm{AsH}_{3}\right)$ from the gas-liquid separator to the electrically heated quartz tube. The electrodeless discharge lamp was used for this determination. The atomic absorption signal was measured as a peak height mode providing an analytical curve. The peristaltic pump, injection time and data acquisition were controlled through Perkin Elmer AAwinlab atomic absorption software version 3.2.

Ultrasound assisted extraction was done in an ultrasound bath at a maximum power of 640 W and a frequency of $35 \mathrm{kHz}$ (Sonorex Digitec DT $510 \mathrm{H}$, Bandelin, Germany).

\section{Sample materials}

Chilli samples were obtained from Department of Plant Science and Agricultural Resources, Faculty of Agriculture, Khon Kaen University, Khon Kaen, Thailand. Three varieties of them were used in this study including the so-called "Yodson Mordindaeng", "Super-hot" and "Erawa". The samples were soaked and washed clean with water. They were dried in an oven at $60{ }^{\circ} \mathrm{C}$ for $48 \mathrm{~h}$. Each kind of the sample was grouped sampling as a whole and the fruit was also separated in different parts as seed, pericarb and placenta. The ground samples in sealed plastic bag were stored in desiccator before use. 


\section{Sample preparation}

The sample preparation was prepared by an ultrasonic assisted extraction (UAE) method for the arsenic speciation determination by FI-HGAAS. Sample amounts of $0.2 \mathrm{~g}$ were weighed and transferred into a $50 \mathrm{~mL}$ polypropylene bottles followed by $10 \mathrm{~mL}$ of the mixed acid leaching solution $\left(7.5 \mathrm{~mL}\right.$ of $1 \mathrm{M} \mathrm{HCl}$ and $2.5 \mathrm{ml}$ of $1 \mathrm{M} \mathrm{HNO}_{3}$ ). After that, $1.5 \mathrm{~mL}$ of $\mathrm{H}_{2} \mathrm{O}_{2}(30 \%, \mathrm{v} / \mathrm{v})$ was added. The extraction bottles were then subjected individually to an ultrasound energy corresponding to ultrasonication for $15 \mathrm{~min}$ to leach the arsenic from the sample into the acid solution. After sonication, the obtained acid extracts were separated from the remaining solid materials using centrifugation at $5000 \mathrm{rpm}$ for $5 \mathrm{~min}$, followed by filtration using Whatman filter paper No. 1 (Ø $55 \mathrm{~mm}$ ) into $10 \mathrm{~mL}$ volumetric flask. The optimum conditions for this sample preparation were certainly studied by the UAE method. The parameters affecting on the absorbance of As were investigated as follows.

\section{Effects of sample amount and solvent volume}

The effect of sample amount was investigated by varying the amounts of the ground chilli sample ranging from $0.05-0.40 \mathrm{~g}$. The solvent volume (of the dilute acid) was varied with $5,10,15$ and $20 \mathrm{~mL}$ according to the fixed ratio of the sample amount.

\section{Effects of type of dilute acid and acid concentration}

Various types of the dilute acid solution were investigated for an extraction solvent including hydrochloric acid, nitric acid and their mixed ratios of these acids. The acid concentration of each of $\mathrm{HCl}$ and $\mathrm{HNO}_{3}$ or the mixed ratios of these acids was studied in the range of 1-6 M.

\section{Effect of hydrogen peroxide}

In addition, volume of $30 \%(\mathrm{w} / \mathrm{w})$ hydrogen peroxide $\left(\mathrm{H}_{2} \mathrm{O}_{2}\right)$ used as auxiliary mild oxidation was investigated in the range of $0-10 \mathrm{~mL}$.

\section{Effect of extraction time}

The effect of extraction time was investigated by varying the ultrasonic sonication time from 1-20 minutes.

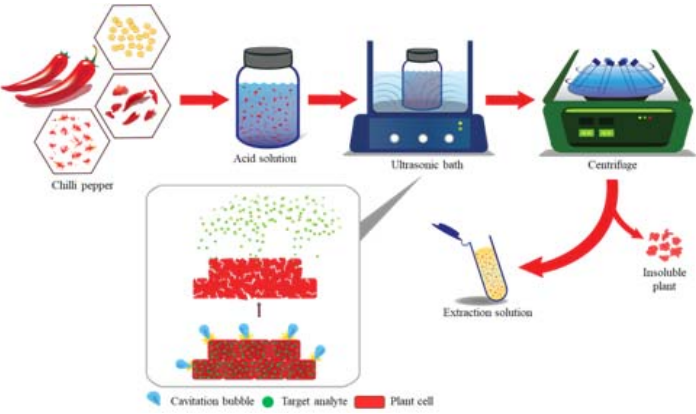

Fig. 1. Graphical procedure of the UAE method for As extraction

\section{Arsenic speciation analysis in real sample}

A $5 \mathrm{ml}$ of the sample extract was pipetted into $10 \mathrm{~mL}$ volumetric flask and made up the final volume with $10 \%(\mathrm{v} / \mathrm{v})$ hydrochloric acid prior to determination by FI-HGAAS by using its calibration graph of As"l' standard solution. A $5 \mathrm{~mL}$ of the sample extract was pipetted into $10 \mathrm{~mL}$ volumetric flask. After that, $1 \mathrm{ml}$ of $2 \%(\mathrm{w} / \mathrm{v})$ thiourea solution was added and diluted to the mark with $10 \%(\mathrm{v} / \mathrm{v})$ hydrochloric acid. This extract solution was left to stand with common hand shake for $30 \mathrm{~min}$ at room temperature prior to determination by FI-HGAAS by using its calibration graph of As"ll standard solution in the presence of $2 \%(\mathrm{w} / \mathrm{v})$ thiourea solution. Since $A s^{\vee}$ will be reduced to be As ${ }^{\text {III }}$ for $\mathrm{AsH}_{3}$ determination, the content of $\mathrm{As}^{\mathrm{v}}$ is then calculated by difference in total inorganic As and that of original As"II. Alternatively, total As content in the sample extracts can be determined directly by FAAS for comparison, if their trace amounts are found in the instrument's linear range.The accuracy of the proposed method was expressed in terms of recovery. The recovery was studied by spiking a known concentration of standard solution into samples before analysis in three replicates. The recovery study of each arsenic species was investigated. The $A s^{\prime \prime \prime}$ and $A s^{v}$ at the concentration of $10 \mathrm{\mu g} \mathrm{L}^{-1}$ were spiked into the real samples.

\section{Determination of arsenic(III), arsenic(V) and total arsenic by FI-HGAAS and FAAS}

At least five step dilutions for working solution of $10 \mathrm{\mu gL}^{-1}(\mathrm{ppb}) \mathrm{As}^{\text {III }}$ was prepared from its stock solution (1000 $\mathrm{mgL}^{-1}$ ) in $25 \mathrm{ml}$ volumetric flask with with $10 \%(\mathrm{v} / \mathrm{v})$ hydrochloric acid. For $10 \mathrm{\mu gL}^{-1}$ (ppb) working solution of $\mathrm{As}^{\mathrm{v}}$, it was also prepared 
in the same manner as done for As'I". The working solution of $A s^{\prime \prime \prime}$ or $A s^{\vee}$ was prepared daily. The calibration standard curve was established using the standard solution prepared in $10 \%(\mathrm{v} / \mathrm{v})$ hydrochloric acid by dilution from the working solution of As'I". The standard As"I solution was obtained with the series of 1.0, 2.0, 3.0, 4.0 and 5.0 $\mathrm{\mu gL}^{-1}$ prior to determination by FI-HGAAS.

For $\mathrm{As}^{\vee}$ analysis, the calibration standard solution was prepared with various volumes of the $\mathrm{As}^{\mathrm{v}}$ working solution, which was pipetted into 10 $\mathrm{mL}$ volumetric flask. After that, $1 \mathrm{~mL}$ of $2 \%(\mathrm{w} / \mathrm{v})$ thiourea solution was added and then diluted to 10 $\mathrm{mL}$ with $10 \%(\mathrm{v} / \mathrm{v})$ hydrochloric acid. Various concentrations of the $\mathrm{As}^{\mathrm{v}}$ solution were also prepared daily in the series of 1.0, 2.0, 3.0, 4.0 and $5.0 \mathrm{MLL}^{-1}$. The $\mathrm{As}^{\mathrm{v}}$ content was then calculated from difference in their contents between total As and As"'.".

The pre-reducing agent to reduce $\mathrm{As}^{\vee}$ to As'II species was adopted from previous report (Thaharn et al., 2014).A 2.0\% (w/v) thiourea solution was prepared by dissolving $2.0 \mathrm{~g}$ of thiourea (MW $76.12 \mathrm{~g} \mathrm{~mol}^{-1}$ ) to $100 \mathrm{~mL}$ volumetric flask with deionized water. The thiourea solution was prepared daily. $\mathrm{A} 5.00 \mathrm{ml}$ of the $\mathrm{As}^{\vee}$ working solution was pipetted into $10 \mathrm{ml}$ volumetric flask. After that, 1 $\mathrm{ml}$ of $2 \%(\mathrm{w} / \mathrm{v})$ thiourea solution was added and then diluted to $10 \mathrm{~mL}$ with deionized water. This solution was left to stand for $10-60 \mathrm{~min}$. at room temperature prior to determine by FI-HGAAS.

A $0.5 \%(\mathrm{w} / \mathrm{v})$ sodium borohydride was prepared by dissolving an accurate amount of $\mathrm{NaBH}_{4}$ in $0.04 \%(\mathrm{w} / \mathrm{v}) \mathrm{NaOH}$. This solution was freshly prepared prior to use each time. A $1 \%(\mathrm{v} / \mathrm{v})$ hydrochloric acid solution was prepared by dilution of $27.02 \mathrm{~mL}$ of $37 \%(\mathrm{w} / \mathrm{v})$ hydrochloric acid to 1000 $\mathrm{mL}$ volumetric flask with deionized water. A 10\% (v/ v) hydrochloric acid solution was prepared by dilution of $270.26 \mathrm{~mL}$ of $37 \%$ (w/v) hydrochloric acid to $1000 \mathrm{~mL}$ volumetric flask with deionized water.

Alternatively, total As could be determined directly by flame atomic absorption spectrometry (FAAS), if its content laid in the linear calibration curve provided. The calibration standard was established using the standard solution of As"II or $\mathrm{As}^{\vee}$ containing a series of $2.0,4.0,6.0,8.0$, and $10.0 \mathrm{mgL}^{-1}$ prepared in $10 \%(\mathrm{v} / \mathrm{v})$ hydrochloric acid.

The analytical characteristics of the proposed method for arsenic analysis were investigated under the optimum conditions. The studied parameters were linearity, limit of detection (LOD), limit of quantitation (LOQ), precision and accuracy.

Linearity was obtained from calibration plot. The calibration plots were studied by analysis of standard solution with various concentrations ranging from 0.5 to $100.0 \mu \mathrm{g} \mathrm{L}^{-1}$ of As"'. LOD and $L O Q$ of the proposed method were deduced based on the signal to noise ratio $(\mathrm{S} / \mathrm{N})$ of 3 and 10 , respectively.

The precision of the present method was evaluated in terms of reproducibility and repeatability of the calibration slope. The repeatability (intra-day precision) was achieved by replicating measurements of the calibration slop in a day $(n=10)$. Whereas, reproducibility (inter-day precision) was calculated from the experiments carried out in ten consecutive days $(n=10)$.

\section{RESULTS AND DISCUSSION}

Optimization of pre-reduction agent for arsenic(III), arsenic(V) and total arsenic determination

For inorganic arsenic speciation, As"I in the sample extract must be determined selectively under the optimum conditions by FI-HGAAS. Then, using of a suitable pre-reducing agent to convert a residual part of $A s^{v}$ in the same sample to $A s^{\prime \prime \prime}$ species, including an original As'"I, was conducted and analyzed as total As content. The As ${ }^{v}$ content was determined by difference in between total As and As'I". At this point of view, the pre-reduction reaction of $A s^{v}$ in the sample extract must be completely done in association with constant sensitivity of their calibration curves for either As ${ }^{\text {III }}$ in the absence or in the presence of the pre-reducing agent used. In addition, if necessary, choice of $\mathrm{As}^{\mathrm{V}}$ in the presence of the pre-reducing agent was introduced, its sensitivity might be the same as those of As ${ }^{\text {III }}$ as mentioned above. The reduction reaction 
time of $2 \%(w / v)$ thiourea was investigated in the range of 10-60 min as shown in Fig.1. It was found that 30-40 min gave the highest absorbance among other in this experiment. Thus, 35 min was selected for further experiments.

\section{Optimization of sample preparation}

The sample preparation for chilli by using UAE was carried out. The optimum conditions for UAE were also investigated in detail in order to reduce the plant matrices which might affect the extraction efficiency by varying sample amount extraction time, type of dilute acid, effect of hydrogen peroxide, dilute acid concentration and volume of the extraction solution by a simple optimization method comparing its response in terms of absorbance $(\mathrm{AU})$ of the As content in the selected chili samples.

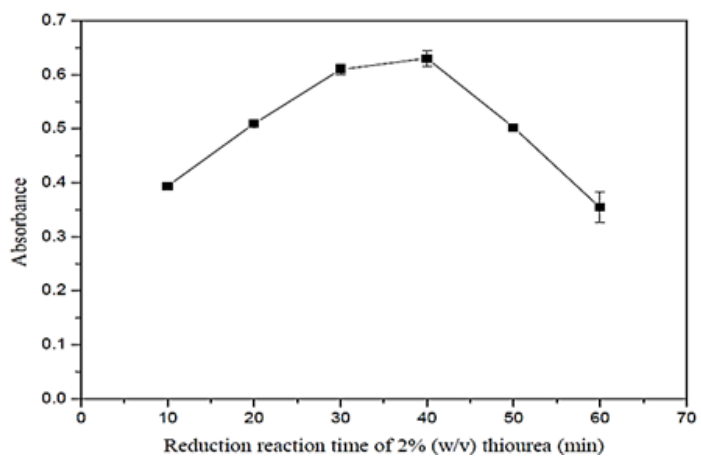

Fig. 1. Effect of the reduction reaction time of $2 \%$ $(w / v)$ thiourea as pre-reduction agent

\section{Effect of amount of sample}

The amount of sample was varied in the range of 0.05 to $0.4 \mathrm{~g}$. The results are shown in Fig.2 (a). It was found that the absorbance of sample was higher than 0.0078 for seed of chilli. Thus, the amount of sample within this range could be used in this procedure. However, in this case, $0.1 \mathrm{~g}$ of the sample was chosen, because it could be applied for determination of arsenic in different parts of the dried chilli samples by both FI-HGAAS and FAAS methods.

\section{Effect of extraction time}

The extraction time is an important factor for sample extraction. This parameter was used for completion of extraction reaction of sample solution. In order to investigate the optimal extraction conditions, the extraction time was varied with 1, 5, 10, 15 and 20 min as shown in Fig.2 (b). From this result, the crude extraction was carried out using 15 min for the samples.

\section{Effect of type of dilute acid}

Under the UAE procedure, the extraction of analytes from solid matrices can easily be performed using an acidic solution. The presence of hydrogen ion $\left(\mathrm{H}^{+}\right)$in liquid phase can leach out the metallic species from the solid sample into the liquid phase as inorganic ions ${ }^{17}$. Nitric acid is frequently reported in studies of the extraction of metals using ultrasonic energy. However, other acid solutions and their mixture have also been reported ${ }^{18}$. In this work, different acid solutions: $\mathrm{HCl}$, $\mathrm{HNO}_{3}$ and two kinds of mixing ratio of $\mathrm{HCl}: \mathrm{HNO}_{3}$ (1:1, 3:1, 1:3, by volume) each at 1.0 Mconcentration were chosen to investigate in details. The results obtained are shown in Fig.2 (c). It was found that high absorbance was obtained using $1 \mathrm{M} \mathrm{HCl}$ : $\mathrm{HNO}_{3}(3: 1, \mathrm{v} / \mathrm{v})$ solution compared with other acid solutions. Thus, next experiment was performed using $1 \mathrm{M} \mathrm{HCl}: \mathrm{HNO}_{3}(3: 1, \mathrm{v} / \mathrm{v})$ solution as a mild acid extraction solvent.

\section{Effect of volume of the extraction solution}

Under the UAE procedure, the volume of the extraction solution was also investigated ranging from $5,10,15$ and $20 \mathrm{ml}$ with the fixed sample amount of $0.2 \mathrm{~g}$. The results obtained are shown in Fig.2(d). It was evident that the absorbance value of As ${ }^{\text {III }}$ was found higher than 0.0037 for the extraction of the seed sample. Therefore, $10 \mathrm{ml}$ of the extraction solution was used as its appropriate ratio.

\section{Effect of hydrogen peroxide}

Hydrogen peroxide is a powerful oxidizing agent that acts via the formation of hydroxyl radicals, which preferably oxidize thiol groups in biomolecules. The volume of hydrogen peroxide was investigated ranging from $0,0.5$, and 1.0-10.0 $\mathrm{mL}$ with $1.0 \mathrm{~mL}$ interval. The absorbance for As determination increased slightly when increasing the volume of hydrogen peroxide from 1.0 to 1.5 $\mathrm{mL}$ as shown in Fig.2 (e). After that the volume reached $1.5 \mathrm{~mL}$, giving a constant trend. Thus, 1.5 $\mathrm{mL}$ of hydrogen peroxide $(30 \%, \mathrm{v} / \mathrm{v})$ was preferably used for further experiment. 


\section{Effect of dilute acid concentration}

Different concentrations of the mixed ratio of $\mathrm{HCl}: \mathrm{HNO}_{3}(3: 1, \mathrm{v} / \mathrm{v})(1,2,3,4,5$ and $6 \mathrm{M})$ were used to evaluate their performance in the extraction procedure. The influence of these acid concentrations for $\mathrm{HCl}: \mathrm{HNO}_{3}(3: 1, \mathrm{v} / \mathrm{v})$ solutions on the absorbance was evaluated by fixing the solution volume, sonication time, sample mass, ultrasonic power and bath temperature. The results obtained are shown in Fig.2 (f). It was found that $1 \mathrm{M} \mathrm{HCl}: \mathrm{HNO}_{3}(3: 1, \mathrm{v} / \mathrm{v})$ solution gave relatively high absorbance. Thus, this acid mixture was preferably used for further experiment.

For UAE optimization conditions, it was found that the mild acid extraction could be done using $10 \mathrm{~mL}$ of the mixed ratio of $1 \mathrm{M} \mathrm{HCl}: \mathrm{HNO}_{3}$ $(3: 1, \mathrm{v} / \mathrm{v})$ and $1.5 \mathrm{~mL}$ hydrogen peroxide with at least $0.1 \mathrm{~g}$ sample for $15 \mathrm{~min}$ extraction time.

\section{Analytical performance characteristics}

The calibration curve and its regression equation were obtained for both $\mathrm{As}^{\prime \prime \prime}$ and $A s^{\vee}$ standard solutions. The calibration curve was
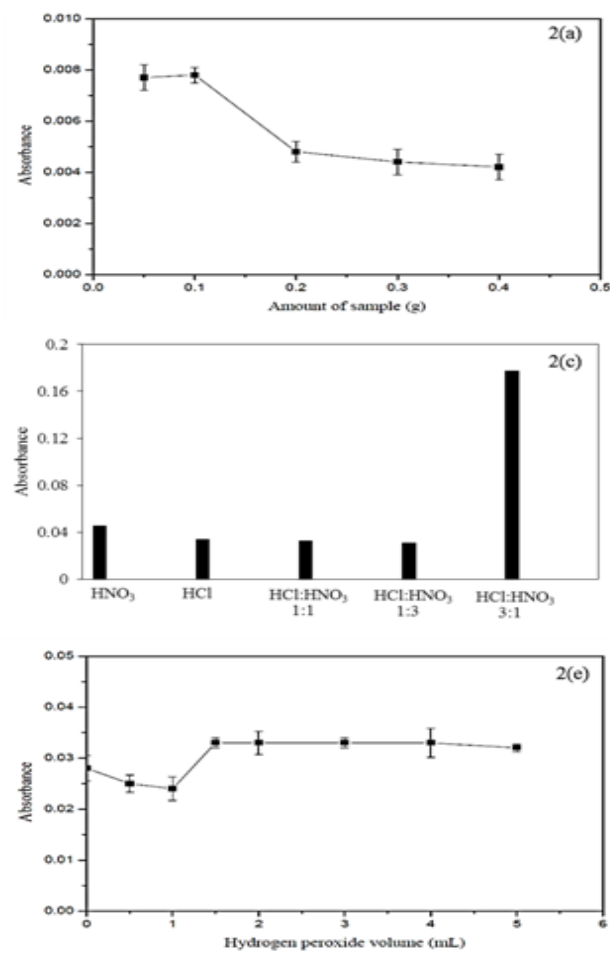

studied between 0.03 and $50.0 \mu \mathrm{g} \mathrm{L}^{-1}$ and the linearity was maintained from 1 to $5 \mu \mathrm{g} \mathrm{L}^{-1}$ with correlation coefficient $\left(\mathrm{r}^{2}\right)$ greater than 0.9995 . The LOD and LOQ were calculated as $3 \mathrm{sb} / \mathrm{S}$ and $10 \mathrm{sb} /$ $S$ respectively ${ }^{19}$; where $s b$ is the blank standard deviation and $S$ is the sensitivity of the method as obtained from the calibration slope. The LODs of FIHGAAS method were $0.026 \mu \mathrm{g} \mathrm{L}^{-1}$ for As'"I and 0.037 $\mu \mathrm{g} \mathrm{L}^{-1}$ for $A s^{v}$. The LOQs of FI-HGAAS method were $0.086 \mu \mathrm{g} \mathrm{L}^{-1}$ for $A s^{\prime \prime \prime}$ and $0.124 \mu \mathrm{g} \mathrm{L}^{-1}$ for $\mathrm{As}^{\mathrm{V}}$. For both LOD and LOQ of FAAS method, they were found to be $0.57 \mathrm{mg} \mathrm{L}^{-1}$ and $1.99 \mathrm{mg} \mathrm{L}^{-1}$, respectively. The precision of the present method is expressed in terms of relative standard deviation (RSD), estimated from 10 replicates and calculated at the concentration of $5 \mathrm{Mg} \mathrm{L}^{-1}$ which was found to be $2.01 \%$ for $A s^{\prime \prime \prime}$ and $3.92 \%$ for $A s^{\vee}$.

\section{Real sample analysis}

The proposed method was applied for the trace determination of inorganic As species in different parts of dried chilli samples under the optimum conditions of UAE and FI-HGAAS. The
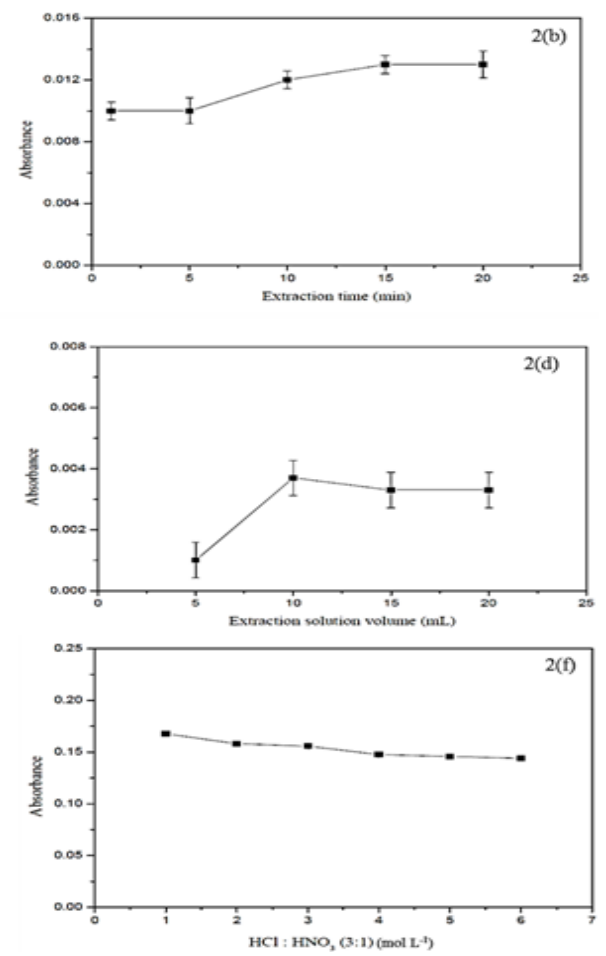

Fig. 2.Optimization of the extraction parameters. (a) Effect of the sample amount. (b) Effect of the extraction time. (c) Effect of different acid solution. (d) Effect of volume of the extraction solvent. (e) Effect of volume of hydrogen peroxide. (f) Effect of dilute acid concentration 
contents of both $A s^{\prime \prime \prime}$ and $A s^{V}$ including total As in three varieties of hot chilli are summarized in Table 1. The ultra-trace amounts of $A s^{\prime \prime \prime}, A s^{v}$ and total arsenic in these chilli samples were found in the ranges of 1.9-10.2 $\mathrm{ng} \mathrm{g}^{-1}, 1.2-19.1 \mathrm{ng} \mathrm{g}^{-1}, 3.3-22.4 \mathrm{ng}$ $\mathrm{g}^{-1}$, respectively. The recovery was studied by spiking of each $10 \mu \mathrm{g} \mathrm{L}^{-1}$ standard solution of $\mathrm{As}^{\mathrm{III}}, \mathrm{As}^{\mathrm{V}}$ and total As into different parts of dried chilli samples for FI-HGAAS measurement and also spiking of each $10 \mathrm{mg} \mathrm{L}^{-1}$ standard solution of As ${ }^{\text {III }}$ into their different parts of these samples for such FAAS measurement. The recovery was calculated as follows ${ }^{20,21}$ :

$$
\text { Recovery }=\frac{C_{\text {spiked }}-C_{\text {nonspiked }}}{C_{\text {added }}} \times 100
$$

where $C_{\text {spiked, }} C_{\text {nonspiked, }}$ and $C_{\text {added }}$ are the concentration of the analyte after addition of a known amount of standard in the real sample, concentration of the analyte in the real sample, and concentration of a known amount of standard that was spiked in the real sample, respectively.

Table. 1: Recovery of spiked $10 \mu \mathrm{g} \mathrm{L}^{-1}$ of $A s^{\prime \prime \prime}, \mathrm{As}^{\mathrm{v}}$ and total As in different parts of chilli samples for $\mathrm{As}^{\mathrm{III}}, \mathbf{A} \mathbf{s}^{\mathrm{v}}$ and total As determination under the optimized conditions of UAE and FI-HGAAS methods

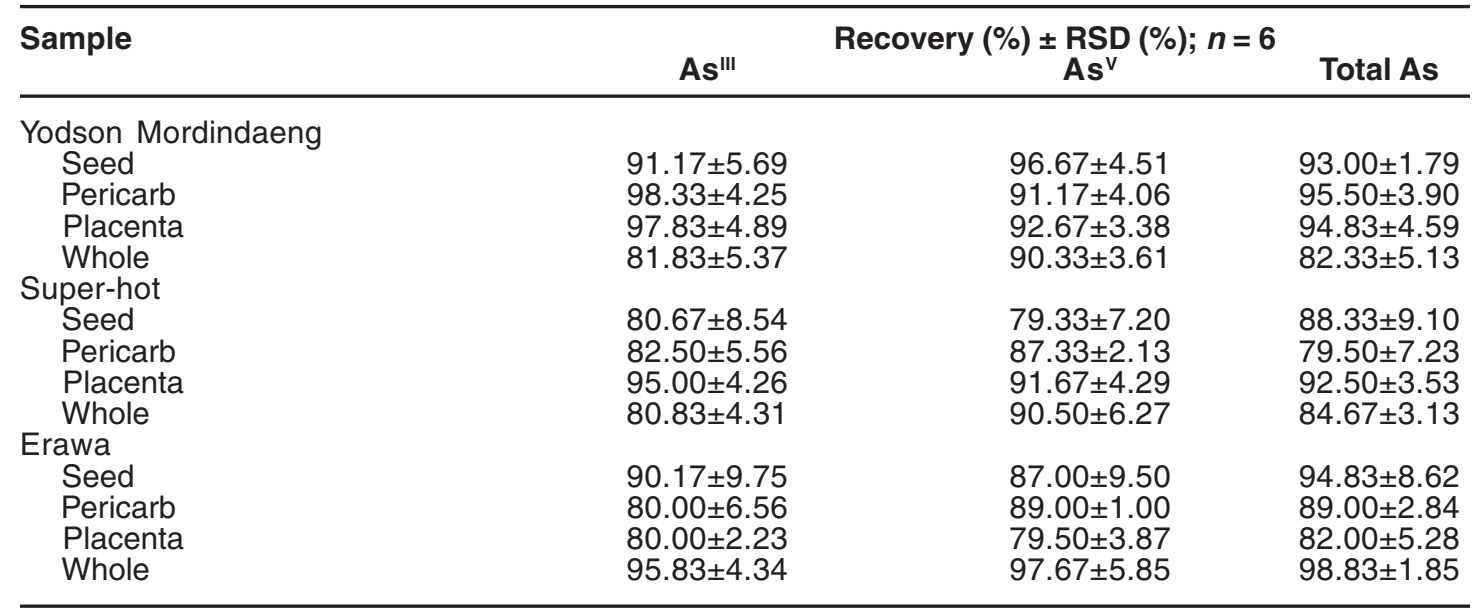

detectable (< LOQ)

Table. 2: The ultra-trace contents of arsenic species in different parts of chilli samples (mean \pm SD) $(n=6)$

\begin{tabular}{|c|c|c|c|}
\hline Sample & As ${ }^{\prime \prime \prime}$ & $\begin{array}{c}\text { Concentration } \underset{\mathrm{As}^{\mathrm{v}}}{\left(\mathrm{ng} \mathrm{g}^{-1}\right)} \pm \mathrm{SD} ; n=6 \\
\end{array}$ & Total As \\
\hline \multicolumn{4}{|c|}{ Yodson Mordindaeng } \\
\hline Seed & $2.6 \pm 0.2$ & $17.9 \pm 0.1$ & $20.8 \pm 0.8$ \\
\hline Pericarb & - & - & - \\
\hline Placenta & - & - & - \\
\hline Whole & $3.3 \pm 0.1$ & $19.1 \pm 0.4$ & $22.4 \pm 0.3$ \\
\hline \multicolumn{4}{|l|}{ Super-hot } \\
\hline Seed & $4.1 \pm 0.4$ & $2.5 \pm 0.6$ & $6.6 \pm 0.3$ \\
\hline Pericarb & $2.3 \pm 0.6$ & $2.1 \pm 0.3$ & $4.5 \pm 0.5$ \\
\hline Placenta & - & - & - \\
\hline Whole & $6.4 \pm 0.6$ & $5.3 \pm 0.6$ & $11.8 \pm 0.3$ \\
\hline \multicolumn{4}{|l|}{ Erawa } \\
\hline Seed & $6.3 \pm 0.3$ & $6.5 \pm 1.9$ & $12.7 \pm 0.2$ \\
\hline Pericarb & $1.9 \pm 0.1$ & $4.2 \pm 0.2$ & $6.2 \pm 0.2$ \\
\hline Placenta & $2.1 \pm 0.2$ & $1.2 \pm 0.6$ & $3.3 \pm 0.4$ \\
\hline Whole & $10.2 \pm 0.2$ & $12.3 \pm 0.9$ & $22.4 \pm 0.6$ \\
\hline
\end{tabular}

detectable (< LOQ) 
Under the optimized conditions for the UAE, the method recoveries of total arsenic found in different parts of "Yodson Mordindaeng" hot chilli such as seed (93.82 $\pm 2.37 \%$ ), pericarb (94.93 \pm $0.06 \%)$, placenta $(97.57 \pm 3.25 \%)$ and Whole $(101.6 \pm 3.08 \%)$ determined by FAAS were obtained.Emphasizing on some varieties of the hot chilli, the recoveries of As $s^{\prime \prime \prime}$ for three kinds of the chilli samples used were found in the range of 80.00 to $98.33 \%$. Those of $\mathrm{As}^{\mathrm{v}}$ were ranged of 79.33 to $97.67 \%$, and total As were also found to be 79.50 to $98.83 \%$ as summarized in Table 2 .

\section{CONCLUSION}

UAE as a green approach was described for simple, efficient and rapid determination at ultra-trace level of arsenic in different parts of hot chilli by FI-HGAAS. Their optimized conditions of UAE are certainly investigated in details, in particular several variables that could affect the performance of the extraction method. In this study, arsenic species, As ${ }^{\mathrm{III}}$ and $\mathrm{As}^{\vee}$ were determined in three varieties of hot chilli as a whole with respect to their seed, pericarb and placenta. In fact, the arsenic content found in seed has paid more attention because the arsenic accumulation in seed of plant can be regulated by inositol transporters. In addition, this study leads to improve such mild acid extraction method as a routine work for other metal residues in foods and vegetables with its green emerging applications for future trends.

\section{ACKNOWLEDGEMENTS}

This research was financially supported by the Higher Research Promotion and National Research University Project of Thailand, Office of the Higher Education Commission, through the Food and Functional Food Research Cluster of Khon Kaen University, and Materials Chemistry Research Center, and Center for Innovation in Chemistry (PERCH-CIC), Commission on Higher Education, Ministry of Education Thailand.

\section{REFERENCES}

1. Sricharoen, P.; Techawongstein, S.; Chanthai, S. J. Food Sci. Technol. 2015, 52, 8077-8085.

2. Sricharoen, P.; Lamaiphan, N.; Patthawaro, P.; Limchoowong, N.; Techawongstien, S; Chanthai, S. Ultrason. Sonochem. 2017, 38, 629-639.

3. Costa, B.E.D.S.; Coelho, N.M.M.; Coelho, L.M. Food Chem. 2015, 178, 89-95.

4. Sricharoen, P.; Limchoowong, N.; Areerob, Y.; Nuengmatcha, P.; Techawongstien, S.; Chanthai, S. Ultrason. Sonochem. 2017, 37, 82-92.

5. Limchoowong, N.; Sricharoen, P.; Areerob, Y.; Nuengmatcha, P.; Sripakdee, T.; Techawongstien, S.; Chanthai, S. Food Chem. 2017, 230, 388-397.

6. Gupta, J.; Gupta, A.; Gupta A.K. Orient. J. Chem. 2014,30(2), 815-819.

7. Kumaravel, S.; Alagusundaram, K. Orient. J. Chem. 2014, 30(2), 631-636.

8. Michael, C.; Sugumar, R.W. Orient. J. Chem. 2013, 29(3), 1149-1154.

9. Markovski, J.S.; Đokiæ, V.; Milosavljeviæ, M.; Mitriæ, M.; Periæ-Grujiæ, A.A.; Onjia, A.E.;
Marinkoviæ, A.D. Ultrason. Sonochem. 2014, 21(2), 790-801.

10. Sigrist, M.; Hilbe, N.; Brusa, L.; Campagnoli, D.; Beldoménico, H. Food Chem. 2016, 210 , 96-101.

11. Rahman Md.F.; Chakraborty, A.; Das, T. Orient. J. Chem. 2015, 31(4), 2401-2408.

12. Korotkova, T.G.; Ksandopulo, S.J.; Bushumov, S.A. Burlaka, S.D.; Say, Y.V. Orient. J. Chem. 2017, 33(1), 186-198.

13. Leong, J.H.; Ong, K.K.; Zin, W.Y.W.M. Orient. J. Chem. 2016, 32(5), 2407-2403.

14. Sricharoen, P.; Limchoowong, N.; Techawongstien, S.; Chanthai, S. Arabian J. Chem. 2017, https://doi.org/10.1016/j.arabjc. 2016. 12. 020

15. Limchoowong, N.; Sricharoen, P.; Techawongstien, S.; Chanthai, S. Food Chem. 2016, 200, 223-229.

16. Limchoowong, N.; Sricharoen, P.; Techawongstien, S.; Kongsri, S.; Chanthai, S. J. Braz. Chem. Soc. 2017, 28(4), 540-546.

17. de Paula, C.E.R.; Caldas, L.F.S.; Brum, D.M.; Cassella, R.J. J. Pharm. Biomed. Anal. 2013, 74, 284-290. 
18. Deng, J.; Feng, X.; Qu, X. Chem. Eng.J.2009, 20. Limchoowong, N.; Sricharoen, P.; 152(1), 177-182.

19. Sricharoen, P.; Limchoowong, N.; Techawongstien, S.; Chanthai, S. Food Chem. 2017, 230, 398-404.

Techawongstien, S.; Chanthai, S. Food Chem. 2016, 203, 386-393.

21. Limchoowong, N; Tan-Umporn, P.; Laijungred, L.; Techawongstein, S.; Chanthai, S.; Orient. J. Chem. 2015, 31(1), 171-176. 